\title{
Article \\ Constant-Current Gate Driver for GaN HEMTs Applied to Resonant Power Conversion
}

\author{
Héctor Sarnago, Óscar Lucía *D, Iulian O. Popa and José M. Burdío
}

check for updates

Citation: Sarnago, H.; Lucía, Ó.;

Popa, I.O.; Burdío, J.M.

Constant-Current Gate Driver for GaN HEMTs Applied to Resonant Power Conversion. Energies 2021, 14, 2377. https://doi.org/10.3390/ en14092377

Academic Editor: Julien Buckley

Received: 5 April 2021

Accepted: 20 April 2021

Published: 22 April 2021

Publisher's Note: MDPI stays neutral with regard to jurisdictional claims in published maps and institutional affiliations.

Copyright: (c) 2021 by the authors. Licensee MDPI, Basel, Switzerland. This article is an open access article distributed under the terms and conditions of the Creative Commons Attribution (CC BY) license (https:// creativecommons.org/licenses/by/ $4.0 /)$.
Department of Electronic Engineering and Communications, University of Zaragoza, I3A., 50018 Zaragoza, Spain; hsarnago@unizar.es (H.S.); iulian@unizar.es (I.O.P.); burdio@unizar.es (J.M.B.)

* Correspondence: olucia@unizar.es

\begin{abstract}
New semiconductor technology is enabling the design of more reliable and high-performance power converters. In particular, wide bandgap (WBG) silicon carbide ( $\mathrm{SiC}$ ) and gallium nitride (GaN) technologies provide faster switching times, higher operating temperature, and higher blocking voltage. Recently, high-voltage GaN devices have opened the design window to new applications with high performance and cost-effective implementation. However, one of the main drawbacks is that these devices require accurate base current control to ensure safe and efficient operation. As a consequence, the base drive circuit becomes more complex and the final efficiency is decreased. This paper presents an improved gate driver circuit for GaN devices based on the use of a constant current regulator (CCR). The proposed circuit achieves constant current regardless of the operating conditions, solving variations with temperature, aging and operating conditions that may degrade the converter performance. Besides, the proposed circuit is reliable and cost-effective, being applicable to a wide range of commercial, industrial and automotive applications. In this paper, its application to a zero-voltage switching resonant inverter for domestic induction heating was performed to prove the feasibility of this concept.
\end{abstract}

Keywords: resonant power conversion; gallium nitride; wide bandgap devices; inverter; induction heating

\section{Introduction}

The development of new semiconductor technology has opened the window to the development of new power conversion systems with improved performance and reliability. In particular, in the past years, WBG devices [1,2] have enabled the development of a new range of power conversion systems with improved efficiency, performance [3,4], and power density. Nowadays, cost reduction in SiC technology [2] together with the development of high-voltage GaN devices are fostering innovation in this field. However, driving these devices in an efficient and safe way is still a significant challenge [5-7]. This paper focuses on the design and implementation of a new gate driver circuit for high-voltage GaN devices.

New GaN devices can be classified into two categories [8]: planar lateral conduction devices, manufactured using Si [9] or SiC [10] substrates, and vertical conduction devices, manufactured using homoepitaxial structures. Nowadays, the former provide more maturity and cost-effectiveness, as well as bigger wafer sizes, whereas the latter provide higher breakdown voltage, mitigate current collapse effect, and make it easier to increase power density. Using these technologies, the main devices currently available are gallium nitride diodes and high electron mobility transistors [11,12] (HEMT), HEMT devices using cascode configurations [13], and GaN MOSFETs [14,15]. However, gate drive circuits are still challenging in both technologies [16]. Typically, cascode devices feature a gate drive design similar to conventional Si MOSFETs [17]. However, e-mode GaN HFETs have more challenging gate driver requirements [18]. This is mainly because the threshold voltage of an e-mode HFET is much lower, typically in the range of 1 to $2 \mathrm{~V}$, and the driving voltage 
is recommended to be close to $5 \mathrm{~V}$ [18]. In GaN devices, there is an additional known issue regarding gate rupture, where small gate voltage overshoots may destroy the device and constant current is often required to optimize its operation. Finally, the gate current must be accurately controlled with regard to the operating conditions, i.e., temperature, to achieve efficient operation [19]. In this context, several approaches have been followed in the past, including the use of resonant drivers for efficient high-frequency operation [20] and IC gate driver solutions [21]. However, most of these are focused on HEMT devices [22] and do not focus on providing accurate voltage/current control.

In this paper, an optimized gate drive circuit is proposed, aimed at improving the performance of $\mathrm{GaN}$-based series resonant inverters. A relevant domestic application of induction heating (IH) was selected as an application target [23-26] (Figure 1). The proposed driver is based on a constant current regulator (CCR), which achieves accurate constant current/voltage control regardless of the operating conditions. Besides, it enables reliable and cost-effective implementation. The proposed circuit was tested using a zerovoltage switching (ZVS) resonant inverter applied to domestic induction heating (IH), proving the feasibility of this proposal.

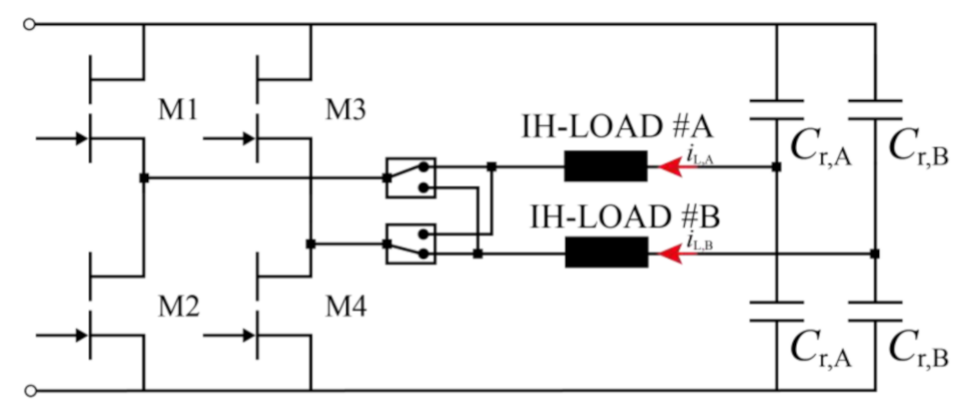

(a)

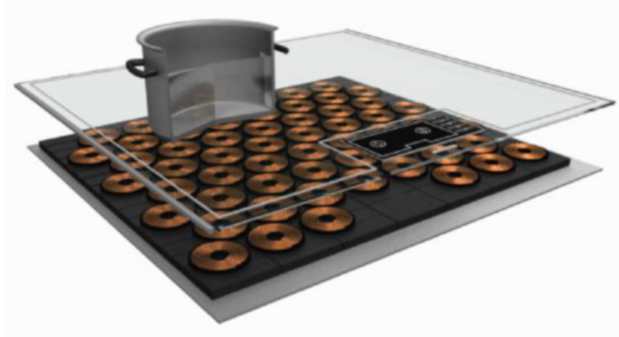

(b)

Figure 1. ZVS full-bridge series resonant inverter applied to domestic induction heating (a) and modern multi-coil appliance (b).

This paper is organized as follows. In Section 2, the proposed optimized gate drive circuit is proposed, detailing the limits of current approaches and benefits of the proposed circuit. The main implementation and experimental results are discussed in Section 3. Finally, Section 4 summarizes the main conclusions of this paper.

\section{Optimized Gate Drive Circuit Proposal}

\subsection{State-of-the-Art Configuration}

In this paper, a full-bridge series resonant inverter (Figure 1) was selected as a reference example for high-performance domestic induction heating applications due to its excellent cost-performance trade-off [27-29]. It is composed of two half-bridge branches, each one composed of two transistors, M1-M2 and M3-M4, respectively, and the resonant tank. In the proposed application, the target pot to be heated together with the resonant capacitor form the resonant tank. These elements were electrically modeled as a series equivalent resistance and inductance [30]. It is important to note that inverters for domestic $\mathrm{IH}$ are usually operated above the resonant frequency in order to obtain high-efficiency and smooth operation thanks to zero-voltage switching during the turn-on transition [31].

Currently, the leading market technology is based on IGBT devices due to their maturity, ruggedness, and cost in the typical operating ranges. However, the recently developed high-voltage GaN devices open the window to new high-performance designs due to the possibility of operating at higher frequencies with higher efficiency, thus reducing the power consumption during the cooking process [32]. However, in this scenario, one of the main challenges is the design of a more complex driver. In order to address this challenge, a new high-performance and cost-effective gate drive circuit is proposed in the next subsection. 
Nowadays, state-of-the-art gate driver circuits (Figure 2) include combinations of pushpull configurations with independently tuneable turn-on and turn-off transitions through $R_{\text {on }}$ and $R_{\text {off. }}$. In ZVS configurations, turn-off transition is selected to be fast, whereas lossless turn-on transitions are slower to minimize EMC issues [33]. WBG devices, however, often require enhanced initial peak current to achieve fast transitions. To achieve this, state-ofthe-art drivers often include a series capacitor $C_{\mathrm{s}}$. Finally, $R_{\mathrm{ss}}$ ensures the required holding current for $\mathrm{GaN}$ devices. However, these configurations do not guarantee the stable gate current required by modern GaN HEMTs, which depends on $v_{\mathrm{d}}, v_{\mathrm{gs}}$ and $R_{\mathrm{ss}}$. This is especially critical in real applications where temperature, operating condition changes, ageing, tolerances, or driver voltage variations, especially in bootstrap implementations, affect the converter operation and reliability.

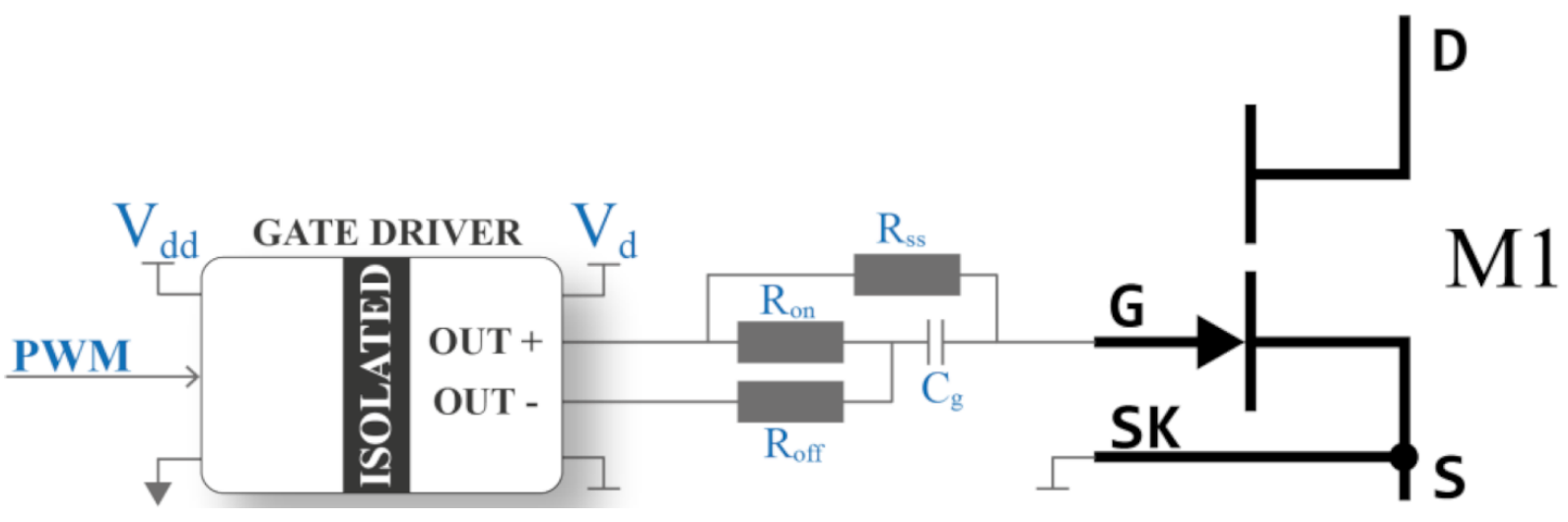

Figure 2. State-of-the-art driver scheme for improved turn on/off transitions.

As an example, Figure 3 a shows the $i_{\mathrm{d}}$ vs. $v_{\mathrm{ds}}$ curves for the IGT60R070D1 CoolGaN enhancement-mode transistor from Infineon. From this figure, it is clear that changes in gate current severely affects the device performance. Figure $3 \mathrm{~b}$ illustrates the change in $v_{\mathrm{gs}}$ with temperature, which is only one of the variables that may impact the driver performance. According to this figure, it is also clear that the operating conditions can change the driver polarization point, leading to significantly degraded performance.

\subsection{Proposed Gate Drive Circuit}

In order to optimize the gate drive circuit and to avoid the aforementioned issues, the circuit shown in (Figure 4) was proposed.

The proposed circuit is based on a linear constant current regulator (CCR), $D_{\mathrm{cc}}$ [34] (see operational curve in Figure 5). This device is a simple, cost-effective, and rugged semiconductor designed to enable effective implementation, and it is typically applied for regulating current in LEDs (similar to a constant current diode, CCD). This device is based on self-biased transistor (SBT) technology, and it is able to regulate the current over a wide voltage range. It ensures constant current above the $V_{\text {th }}$ threshold, which is easy to achieve with the proposed driver structure regardless of the operating conditions. It is designed with a negative temperature coefficient to protect circuits from thermal runaway at extreme voltages and currents.

The CCR shows excellent transient performance, making it suitable for switching applications such as the one in this paper, and it is at $25 \%$ of regulation with only $0.5 \mathrm{~V} v_{\text {ak }}$. Furthermore, since it demands no additional external components, it allows cost-effective implementation for both high-side and low-side drivers/regulators. Finally, it is important to note that high anode-cathode voltage ratings can withstand surges common in most industrial applications, making the CCR suitable for the proposed application. In this circuit, the CCR was used to ensure the constant current required by GaN HEMTs. Since this device is oriented towards consumer electronics applications, it provides cost-effective implementation. 


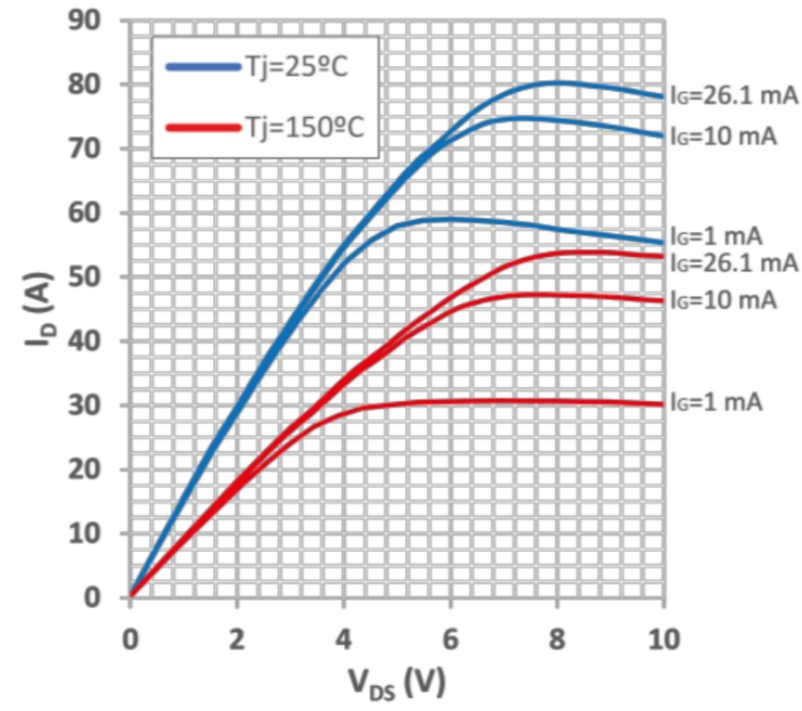

(a)

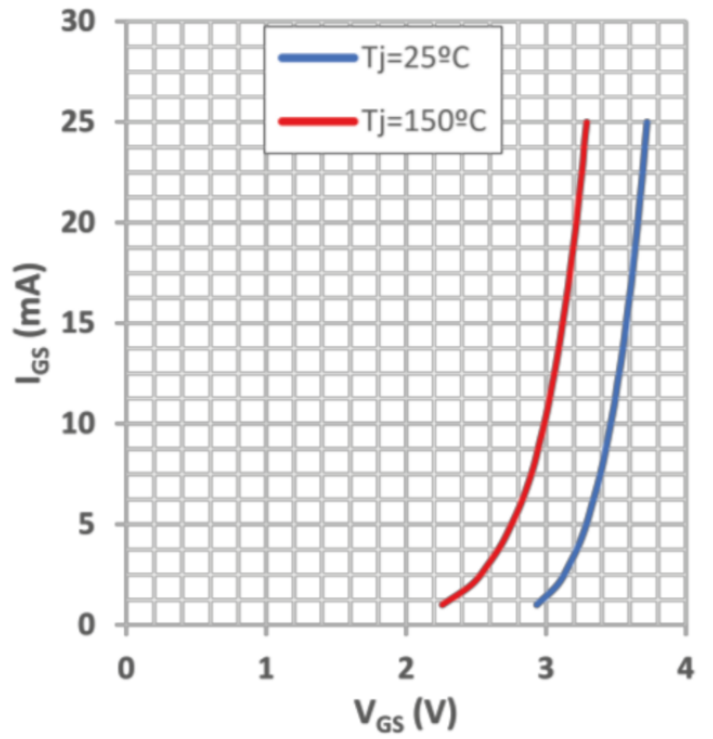

(b)

Figure 3. Reported $i_{\mathrm{d}}$ vs. $v_{\mathrm{ds}}$ curves (a) and experimentally measured base current dependence with temperature (b) for the IGT60R070D1 CoolGaN device from Infineon.

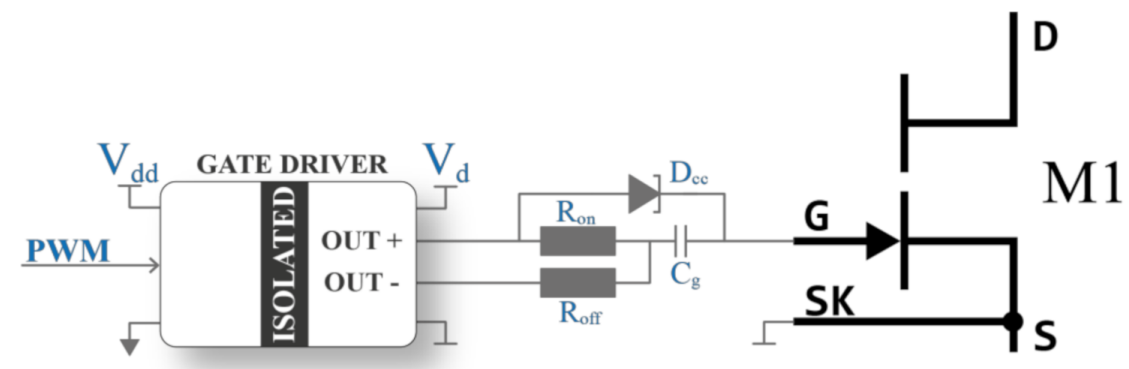

Figure 4. Proposed constant-gate-current driver for GaN devices.

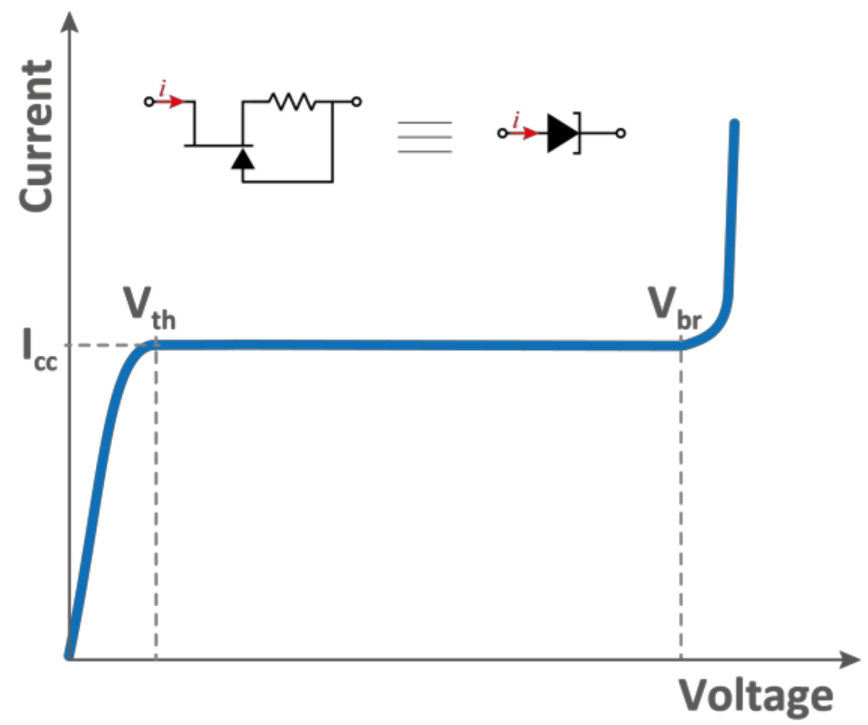

Figure 5. Current-voltage curve for a linear constant current regulator. 


\section{Experimental Results}

In order to prove the feasibility of the proposed gate drive circuit, a GaN-based FPGAcontrolled resonant converter applied to domestic induction heating was designed and implemented. The experimental test-bench was based on the IGT60R070D1 CoolGaN device from Infineon, an e-mode HEMT, and the NSI45025AT1G constant current regulator from OnSemi. This device was selected to provide the $25 \mathrm{~mA}$ constant current required by the GaN power devices. Moreover, this device is a cost-effective component, with a cost of a few cents for large volumes, and is suitable for most applications. Figure 6 shows the experimental prototype with top and bottom views. This prototype was designed so that both the proposed and the state-of-the-art gate drive circuits could be tested with minimum changes required to provide a fair comparison.

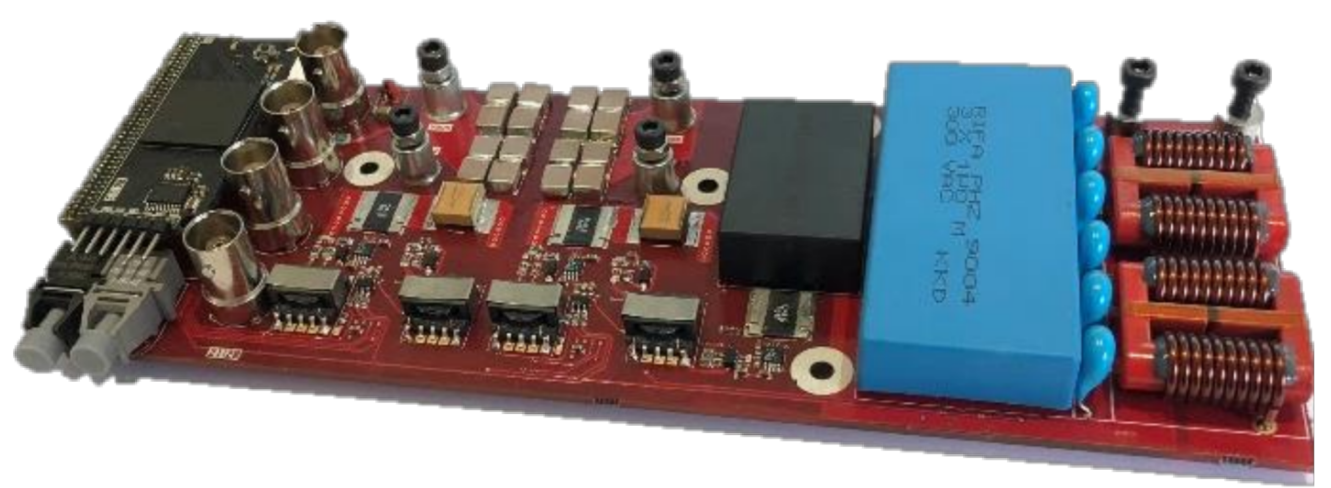

(a)

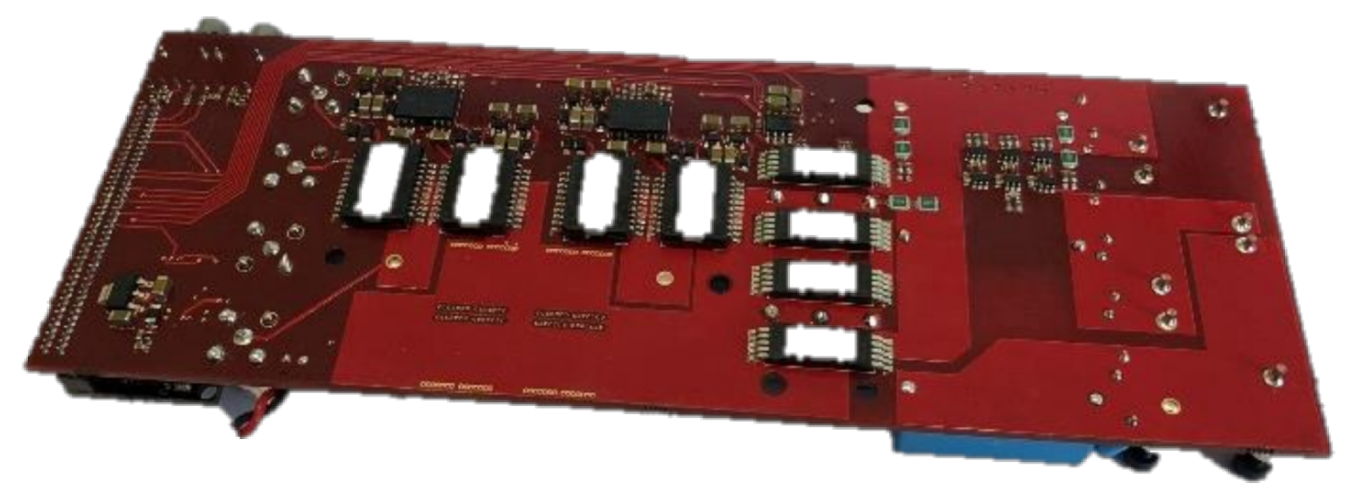

(b)

Figure 6. Experimental prototype: top (a) and bottom (b) views.

Figure 7 shows the main experimental results for the implemented converter operating under different frequency and power operating conditions, ranging from $20 \mathrm{kHz}$ up to $500 \mathrm{kHz}$. In these figures, both the output inverter waveforms and the driving signals can be seen. These results proved the ability of the proposed gate drive circuit to operate properly under a wide range of operating conditions and to provide a stable gate current. These operating conditions exceed the normal operating range of such resonant converters, proving the ability of the proposed driver circuit to provide stable gate current for optimized operation.

An additional interesting aspect of the proposed gate drive circuit is the dynamic performance of the CCR device since these devices are often used in static applications. To analyze this, Figure 8 shows detailed waveforms during turn-on (a) and turn-off (b) transitions, respectively, operating at $100 \mathrm{kHz}$. These measurements show the correct operation of the proposed circuit, validating its dynamic operation. The proposed device provides fast current regulation, which ensures correct device switching without thermal issues due to switching losses. These results, consequently, validate the ability of the 
proposed circuit to operate under fast transition conditions typical of power converters featuring WBG devices.

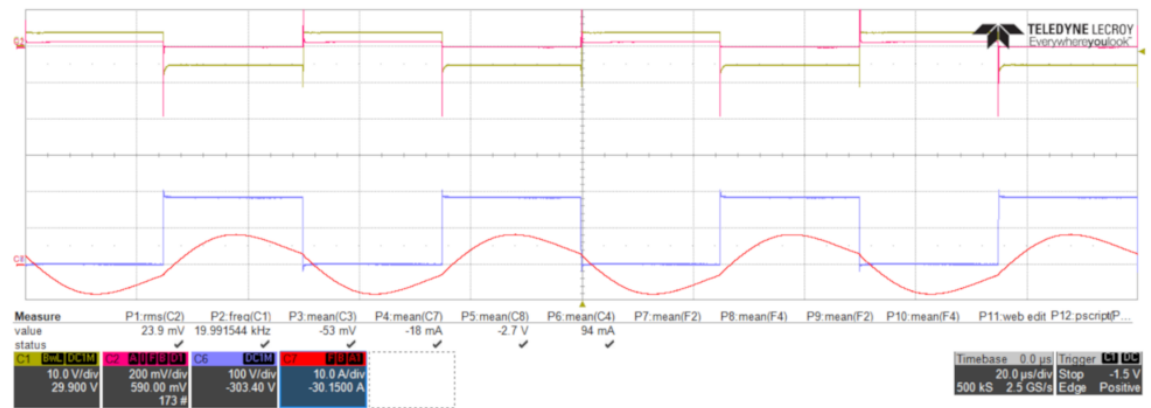

(a)

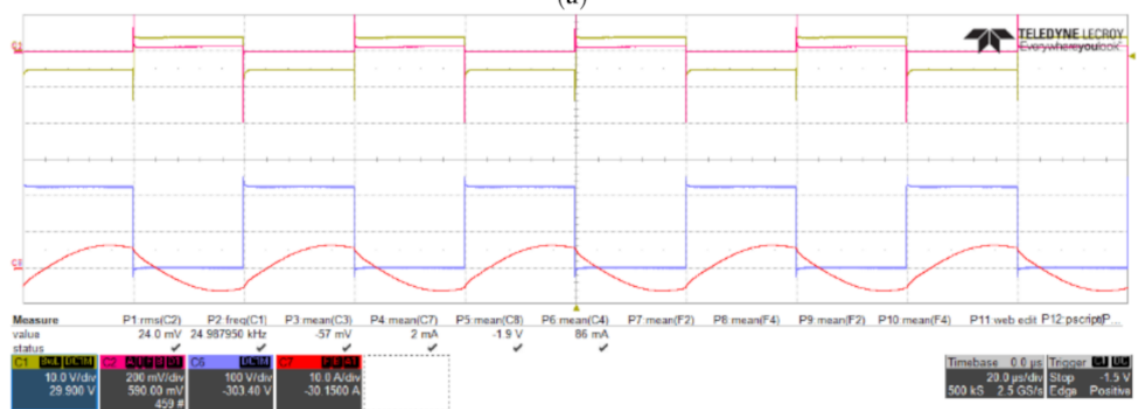

(b)

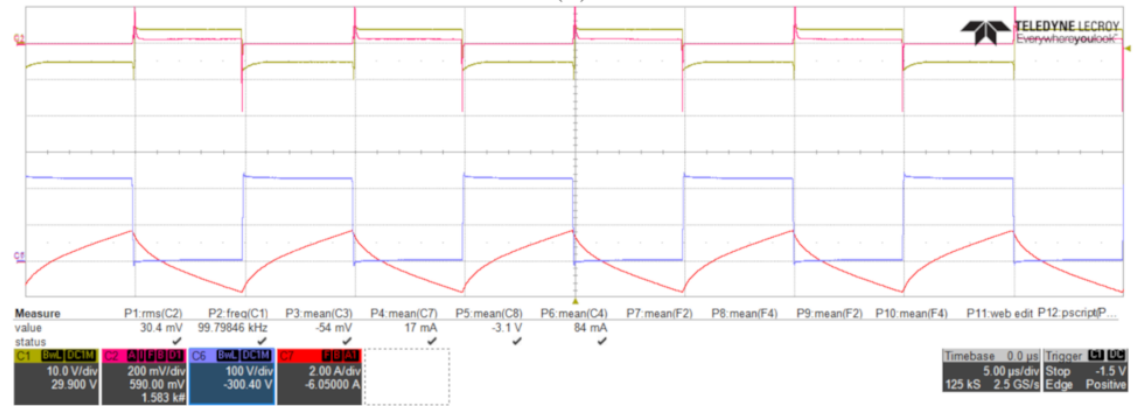

(c)

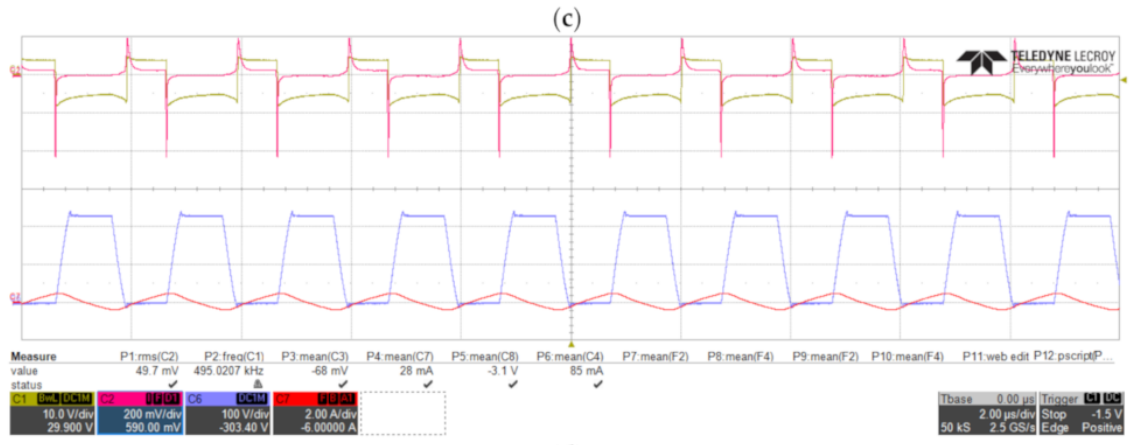

(d)

Figure 7. Experimental measurements. Main waveforms at different operating conditions of the resonant tank: $20 \mathrm{kHz}(\mathbf{a}), 25 \mathrm{kHz}(\mathbf{b}), 100 \mathrm{kHz}(\mathbf{c})$, and $500 \mathrm{kHz}$ (d). From top to bottom: gate voltage $(\mathrm{CH} 1)$ and gate current $(\mathrm{CH} 2)$, inverter output voltage $(\mathrm{CH} 6)$ and inverter output current $(\mathrm{CH} 7)$. The proposed circuit achieves constant gate current regardless of the operating frequency in the proposed resonant converter, ranging from $20 \mathrm{kHz}$ up to $500 \mathrm{kHz}$. 


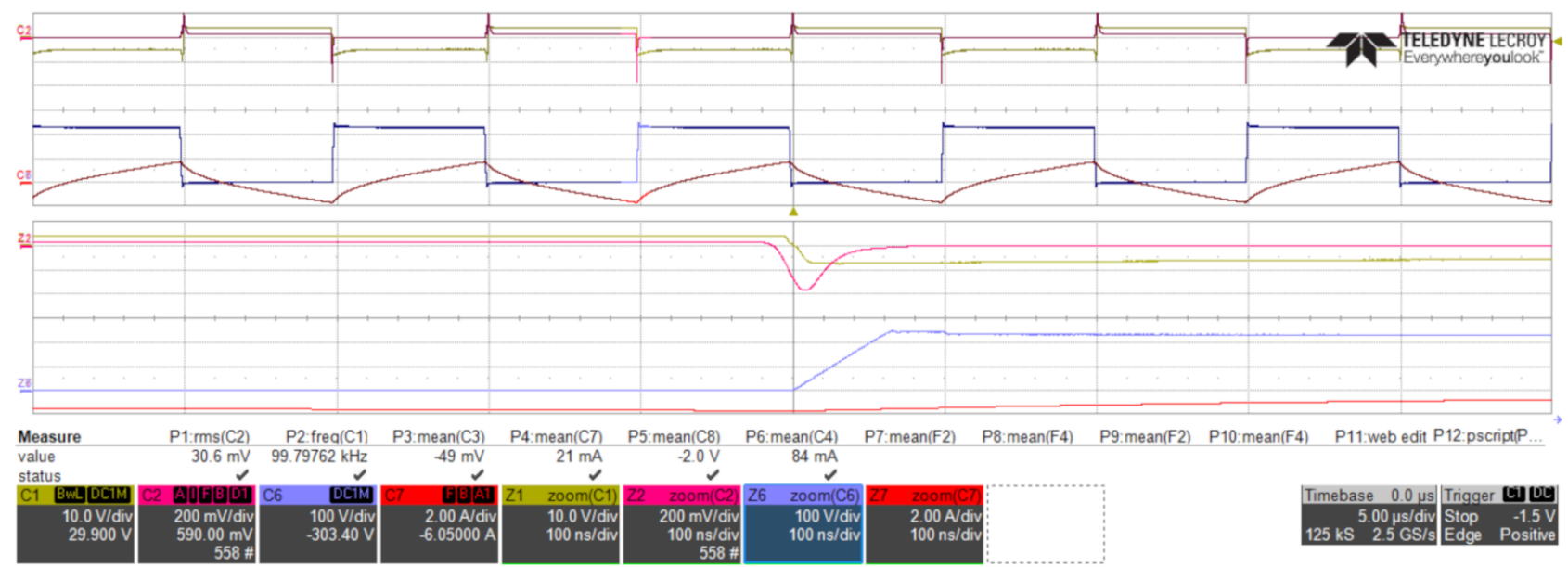

(a)

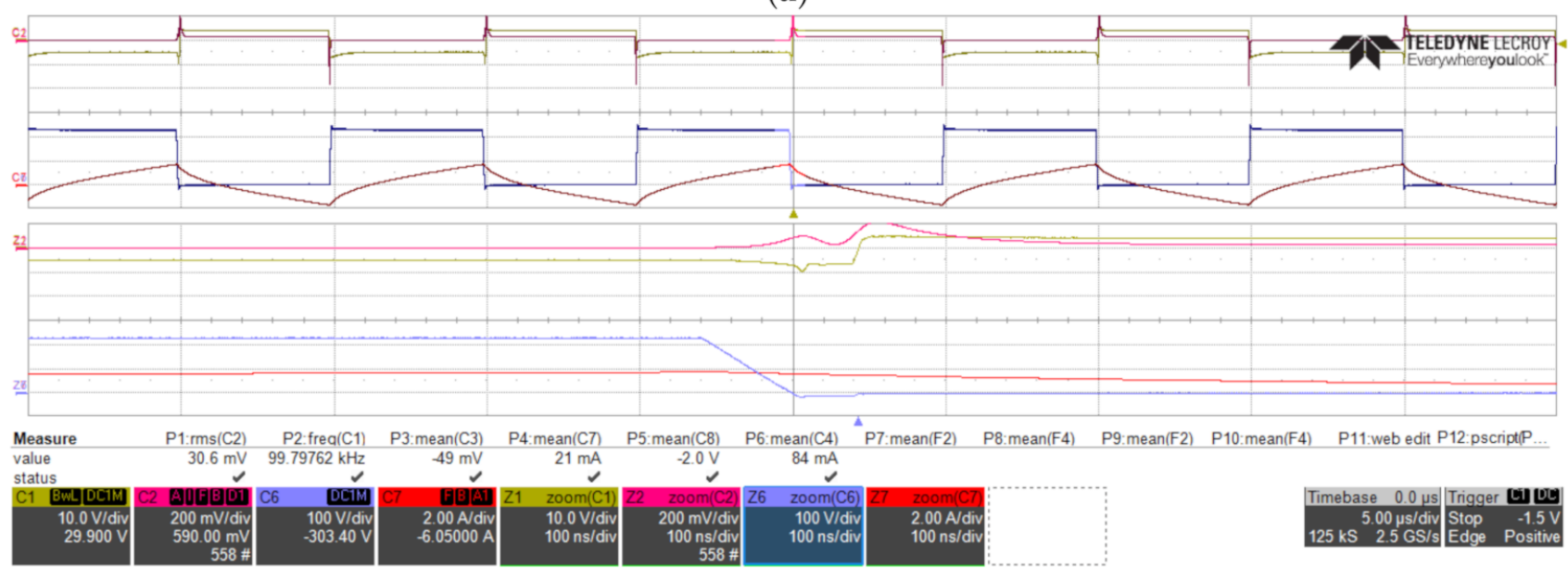

(b)

Figure 8. Experimental measurements at $100 \mathrm{kHz}$. Main waveforms at turn-on (a) and turn-off (b) transitions. From top to bottom: gate voltage $(\mathrm{CH} 1)$ and gate current $(\mathrm{CH} 2)$, inverter output voltage $(\mathrm{CH} 6)$ and inverter output current $(\mathrm{CH} 7)$. The proposed circuit achieves proper transient performance by achieving fast current regulation, which ensures appropriate GaN device switching in the proposed resonant converter.

Finally, Figure 9 shows a comparison of the performance of the proposed driver (a) and the state-of-the-art implementation (b) when changes in the driving voltage occur due either to thermal, aging or bootstrap issues. In these figures, it can be seen that the proposed driver achieves almost constant performance, ensuring safe and reliable operation under real operating conditions. However, due to variations in the driving voltage, the current state-of-the-art driver circuit shows large variations. In this test, these variations resulted in a 22-mA current ripple, i.e., $88 \%$ gate current variation. This may lead to inefficient and/or unreliable operating conditions, proving the benefits of the proposed gate drive circuit.

This set of results proves the correct operation of the proposed gate driver circuit under a wide range of operating conditions and shows its benefits when compared with the state-of-the-art implementation. 

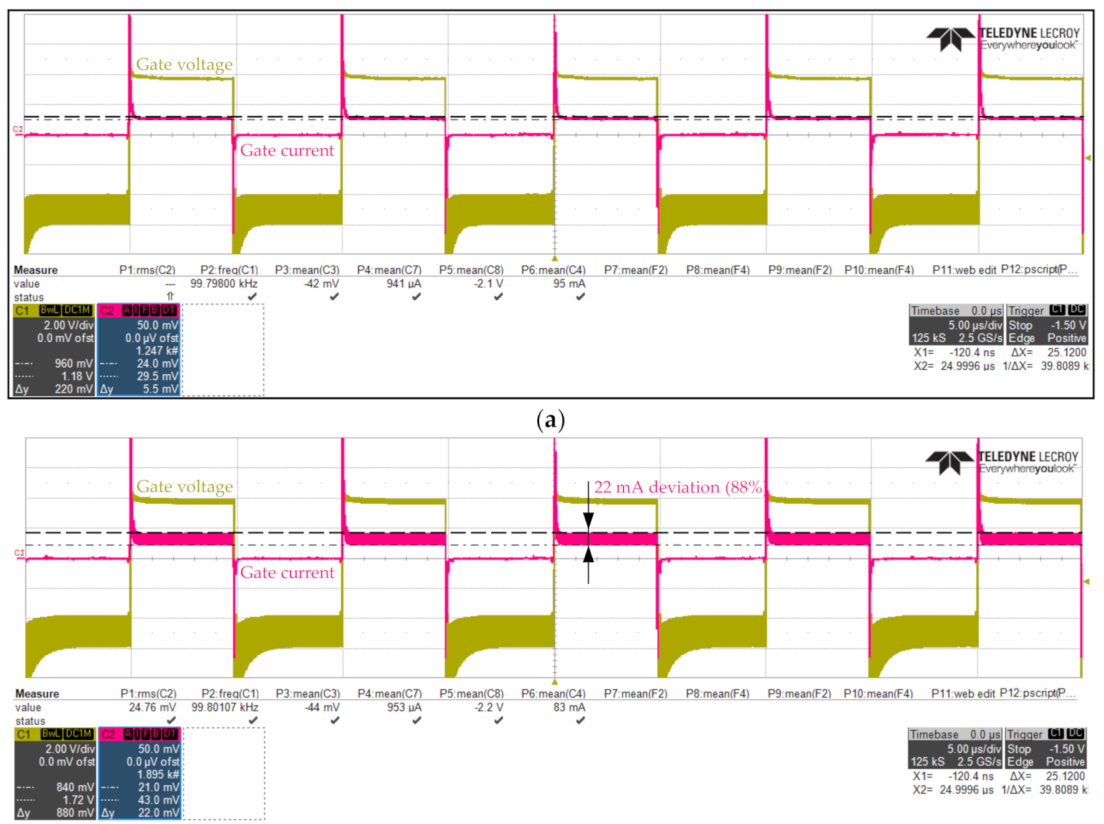

(b)

Figure 9. Experimental measurements at $100 \mathrm{kHz}$ under different driver voltages comparing the proposed driver (a) and the current state-of-the-art implementation (b). The proposed circuit achieves stable gate current ( $\mathrm{CH} 2$, pink) (a) whereas the state-of-the-art approach exhibits large variation (b). From top to bottom: driving voltage $(\mathrm{CH} 1)$ and driving current $(\mathrm{CH} 2)$. The proposed circuit achieves constant current regardless of the operating conditions (a) whereas standard gate driver solutions (b) has wide current variation (up to $22 \mathrm{~mA}, 88 \%$ from nominal), which can cause inefficient power device operation.

\section{Conclusions}

This paper proposed an enhanced gate driver circuit for GaN HEMT devices, which require precise and constant current and voltage for safe and reliable operation. The proposed circuit is based on the use of a linear constant current regulator, which achieves stable operation regardless of the operating conditions. Moreover, the proposed design is cost-effective and reliable and can be used in both low-side and high-side drive circuits in a wide variety of applications. In this paper, an experimental prototype applied to domestic induction heating was designed and implemented, proving the feasibility and benefits of the proposed gate drive circuit. The proposed circuit has the proven ability to operate in a range from $20 \mathrm{kHz}$ up to $500 \mathrm{kHz}$, with fast switching transitions, ensuring the efficiency and reliability of the GaN device. Moreover, it proved to be able to stabilize gate current regardless of the gate driver voltage, providing optimized operation compared to current state-of-the-art gate drive circuits.

Author Contributions: Conceptualization, H.S. and Ó.L.; methodology, H.S. and Ó.L.; validation, H.S., I.O.P. and Ó.L.; writing—original draft preparation, Ó.L.; writing—review and editing, H.S, Ó.L., I.O.P. and J.M.B.; funding acquisition, J.M.B. All authors have read and agreed to the published version of the manuscript.

Funding: This work was supported by the Spanish MICINN and AEI under Project PID2019-103939RB-I00.

Institutional Review Board Statement: Not applicable.

Informed Consent Statement: Not applicable.

Data Availability Statement: The data presented in this article are available on request from the corresponding author.

Conflicts of Interest: The authors declare no conflict of interest. 


\section{References}

1. Millán, J.; Godignon, P.; Perpiñà, X.; Pérez-Tomás, A.; Rebollo, J. A Survey of Wide Bandgap Power Semiconductor Devices. IEEE Trans. Power Electron. 2014, 29, 2155-2163. [CrossRef]

2. She, X.; Huang, A.Q.; Lucia, O.; Ozpineci, B. Review of Silicon Carbide Power Devices and Their Applications. IEEE Trans. Ind. Electron. 2017, 64, 8193-8205. [CrossRef]

3. Wang, Y.; Lucia, O.; Zhang, Z.; Guan, Y.; Xu, D. Review of Very High Frequency Power Converters and Related Technologies. IET Power Electron. 2020, 13, 1711-1721. [CrossRef]

4. Wang, Y.; Lucia, O.; Zhang, Z.; Gao, S.; Guan, Y.; Xu, D. A Review of High Frequency Power Converters and Related Technologies. OJIES 2020, 1, 247-260. [CrossRef]

5. Moradpour, M.; Pirino, P.; Losito, M.; Franke, W.-T.; Kumar, A.; Gatto, G. Multi-Objective Optimization of the Gate Driver Parameters in a SiC-Based DC-DC Converter for Electric Vehicles. Energies 2020, 13, 3720. [CrossRef]

6. Yin, S.; Wu, Y.; Liu, Y.; Pan, X. Comparative Design of Gate Drivers with Short-Circuit Protection Scheme for SiC MOSFET and Si IGBT. Energies 2019, 12, 4546. [CrossRef]

7. Ma, C.-T.; Gu, Z.-H. Review on Driving Circuits for Wide-Bandgap Semiconductor Switching Devices for Mid- to High-Power Applications. Micromachines 2021, 12, 65. [CrossRef]

8. Ding, X.; Zhou, Y.; Cheng, J. A review of gallium nitride power device and its applications in motor drive. CES Trans. Elec. Mach. Sys. 2019, 3, 54-64. [CrossRef]

9. Chen, K.J.; Häberlen, O.; Lidow, A.; Tsai, C.L.; Ueda, T.; Uemoto, Y.; Wu, Y. GaN-on-Si Power Technology: Devices and Applications. IEEE Trans. Electron. Dev. 2017, 64, 779-795. [CrossRef]

10. Rodríguez, M.; Zhang, Y.; Maksimović, D. High-Frequency PWM Buck Converters Using GaN-on-SiC HEMTs. IEEE Trans. Power Electron. 2014, 29, 2462-2473. [CrossRef]

11. Mishra, U.K.; Parikh, P.; Yi-Feng, W. AlGaN/GaN HEMTs-An overview of device operation and applications. Proc. IEEE 2002, 90, 1022-1031. [CrossRef]

12. Keshmiri, N.; Wang, D.; Agrawal, B.; Hou, R.; Emadi, A. Current Status and Future Trends of GaN HEMTs in Electrified Transportation. IEEE Access 2020, 8, 70553-70571. [CrossRef]

13. Huang, X.; Liu, Z.; Li, Q.; Lee, F.C. Evaluation and Application of 600 V GaN HEMT in Cascode Structure. IEEE Trans. Power Electron. 2014, 29, 2453-2461. [CrossRef]

14. Khan, M.A.; Hu, X.; Sumin, G.; Lunev, A.; Yang, J.; Gaska, R.; Shur, M.S. AlGaN/GaN metal oxide semiconductor heterostructure field effect transistor. IEEE Electr. Device Lett. 2000, 21, 63-65. [CrossRef]

15. Hudgins, J.L.; Simin, G.S.; Santi, E.; Khan, M.A. An assessment of wide bandgap semiconductors for power devices. IEEE Trans. Power Electron. 2003, 18, 907-914. [CrossRef]

16. Sarnago, H.; Lucía, O.; Mediano, A.; Burdío, J.M. Improved operation of SiC-BJT-based series resonant inverter with optimized base drive circuit. IEEE Trans. Power Electron. 2014, 29, 5097-5101. [CrossRef]

17. Choi, H.; Park, C.; Kim, J.; Jung, H. Bias-Voltage Stabilizer for HVHF Amplifiers in VHF Pulse-Echo Measurement Systems. Sensors 2017, 17, 2425. [CrossRef]

18. Jones, E.A.; Wang, F.F.; Costinett, D. Review of Commercial GaN Power Devices and GaN-Based Converter Design Challenges. IEEE J. Emerg. Sel. Top. Power Electron. 2016, 4, 707-719. [CrossRef]

19. El-Hamamsy, S.A. Design of high-efficiency RF Class-D power amplifier. IEEE Trans. Power Electron. 1994, 9, 297-308. [CrossRef]

20. Sun, B.; Zhang, Z.; Andersen, M.A.E. A Comparison Review of the Resonant Gate Driver in the Silicon MOSFET and the GaN Transistor Application. IEEE Trans. Ind. Appl. 2019, 55, 7776-7786. [CrossRef]

21. Xie, R.; Xu, G.; Yang, X.; Tang, G.; Wei, J.; Tian, Y.; Zhang, F.; Chen, W.; Wang, L.; Chen, K.J. Modeling the gate driver IC for GaN transistor: A black-box approach. In Proceedings of the 2018 IEEE Applied Power Electronics Conference and Exposition, San Antonio, TX, USA, 4-8 March 2018; pp. 2900-2904.

22. Zhang, Y.; Li, J.; Wang, J. Investigations on Driver and Layout for Paralleled GaN HEMTs in Low Voltage Application. IEEE Access 2019, 7, 179134-179142. [CrossRef]

23. Sarnago, H.; Lucía, O.; Mediano, A.; Burdío, J.M. Class-D/DE dual-mode-operation resonant converter for improved-efficiency domestic induction heating system. IEEE Trans. Power Electron. 2013, 28, 1274-1285. [CrossRef]

24. Pham, H.N.; Fujita, H.; Ozaki, K.; Uchida, N. Estimating method of heat distribution using 3-D resistance matrix for zone-control induction heating systems. IEEE Trans. Power Electron. 2012, 27, 3374-3382. [CrossRef]

25. Sarnago, H.; Lucía, O.; Mediano, A.; Burdío, J.M. Design and implementation of a high-efficiency multiple-output resonant converter for induction heating applications featuring wide bandgap devices. IEEE Trans. Power Electron. 2014, 29, 2539-2549. [CrossRef]

26. Lucia, O.; Navarro, D.; Guillén, P.; Sarnago, H.; Lucia, S. Deep Learning-based Magnetic Coupling Detection for Advanced Induction Heating Appliances. IEEE Access 2019, 7, 181668-181677. [CrossRef]

27. Lucía, O.; Burdío, J.M.; Millán, I.; Acero, J.; Barragán, L.A. Efficiency oriented design of ZVS half-bridge series resonant inverter with variable frequency duty cycle control. IEEE Trans. Power Electron. 2010, 25, 1671-1674. [CrossRef]

28. Lucía, O.; Acero, J.; Carretero, C.; Burdío, J.M. Induction heating appliances: Towards more flexible cooking surfaces. IEEE Ind. Electron. Mag. 2013, 7, 35-47. [CrossRef] 
29. Lucía, O.; Maussion, P.; Dede, E.; Burdío, J.M. Induction heating technology and its applications: Past developments, current technology, and future challenges. IEEE Trans. Ind. Electron. 2014, 61, 2509-2520. [CrossRef]

30. Jiménez, O.; Lucia, O.; Urriza, I.; Barragán, L.A.; Mattavelli, P.; Boroyevich, D. An FPGA-based gain-scheduled controller for resonant converters applied to induction cooktops. IEEE Trans. Power Electron. 2014, 29, 2143-2152. [CrossRef]

31. Lucía, O.; Burdío, J.M.; Millán, I.; Acero, J.; Puyal, D. Load-adaptive control algorithm of half-bridge series resonant inverter for domestic induction heating. IEEE Trans. Ind. Electron. 2009, 56, 3106-3116. [CrossRef]

32. Amano, H.; Baines, Y.; Beam, E.; Borga, M.; Bouchet, T.; Chalker, P.R.; Charles, M.; Chen, K.J.; Chowdhury, N.; Chu, R.; et al. The $2018 \mathrm{GaN}$ power electronics roadmap. IEEE J. Emerg. Sel. Top. Power Electron. 2018, 51, 163001. [CrossRef]

33. Hu, A.P. Selected Resonant Converters for IPT Power Supplies; University of Auckland: Auckland, New Zealand, 2001.

34. On Semiconductor, NSI45025AT1G Constant Current Regulator \& LED Driver Rev. 5 datasheet. In 2014. Available online: https:/ / www.onsemi.com/pdf/datasheet/nsi45025a-d.pdf (accessed on 1 March 2021).

\section{Short Biography of Authors}

Óscar Lucía received the M.Sc. and Ph.D. degrees (with honors) in Electrical Engineering from the University of Zaragoza, Spain, in 2006 and 2010, respectively.

During 2006 and 2007 he held a research internship at the Bosch and Siemens Home Appliances Group. Since 2008, he has been with the Department of Electronic Engineering and Communications at the University of Zaragoza, Spain, where he is currently an Associate Professor. He has been a visiting scholar in the Center for Power Electronics Systems (CPES, Virginia Tech) in 2009 and 2012, and the TU Berlin (Germany) in 2019. His main research interests include resonant power conversion, wide-bandgap devices, and digital control, mainly applied to wireless power transfer, induction heating, electric vehicles, and biomedical applications. In these topics, he has published more than 85 international journal papers and 150 conference papers, and he has filed more than 45 international patents.

Dr. Lucía is an Associate Editor of the IEEE Transactions on Industrial Electronics, the IEEE Transactions on Power Electronics, and the IEEE Open Journal of the Indus-trial Electronics Society. Dr. Lucía is a member of the Aragon Institute for Engineering Research (I3A). 